\section{Reply to the Letter by L. Filik Regarding "Long- term Maintenance Therapy with Rabeprazole for Reflux Esophagitis"}

Key words: nutrition absorption, adverse effect

\section{(Intern Med 50: 1269, 2011)}

(DOI: 10.2169/internalmedicine.50.5422)

I appreciate the letter from Dr. Filik (1) and his question regarding nutrition absorption in our article (2). Proton pump inhibitors (PPIs) have been widely used for gastric acid suppression therapy. PPIs are prescribed for patients of reflux esophagitis for long-term maintenance therapy $(3,4)$, and several studies have demonstrated the efficacy of PPIs for maintenance therapy for reflux esophagitis in Japan (5-7). Several adverse effects are reported for a long period use of PPIs, but these reports are controversial; some reports are positive and others are negative. Dr. Filik asked if PPIs influenced the nutrient absorption in our two-year follow-up study of PPI, rabeprazole (2). This study was a prospective study for the evaluation of maintenance therapy of rabeprazole for reflux esophagitis. Although the study was not designed to evaluate nutrition conditions, neither the serum albumin level nor hemoglobin level was decreased for the two years of follow-up and no malnutrition state was observed. Although it is possible to answer the question partly raised by Dr. Filik, this question might warrant further exploration.
Author's disclosure of potential Conflicts of Interest (COI). Kazuma Fujimoto: Honoraria, Eisai Co., Ltd and Advisory Committees of Eisai Co., Ltd; Research funding, Eisai Co., Ltd

Kazuma Fujimoto

\section{References}

1. Filik L. Long term maintenance therapy with rabeprazole for reflux esophagitis. Intern Med 50: 1267, 2011.

2. Fujimoto K, Hongo M; the Maintenance Study Group. Safety and efficacy of long-term maintenance therapy with oral dose of rabeprazole $10 \mathrm{mg}$ once daily in Japanese patients with reflux esophagitis. Intern Med 50: 179-188, 2011.

3. The Japanese Society of Gastroenterology. Guideline for Treatment of Gastro-Esophageal Reflux Disease. Nankodo, Tokyo, 2009 (in Japanese).

4. Kahrilas PJ, Shaheen NJ, Vaezi MF, et al. American Gastroenterological Association Medical Position Statement on the management of gastroesophageal reflux disease. Gastroenterology 35 : 1383-1391, 2008.

5. Fujimoto K, Hongo M; the Maintenance Study Group. Risk factors for relapse of erosive GERD during long-term maintenance treatment with proton pump inhibitor: a prospective multicenter study in Japan. J Gastroenterol 45: 1193-1200, 2010.

6. Hongo M, Fujimoto K; Gastric Poly Study Group. Incidence and risk factor of fundic gland polyp and hyperplastic polyp in longterm proton pump inhibitor therapy: a prospective study in Japan. J Gastroenterol 45: 618-624, 2010.

7. Ohkusa T, Maekawa T, Arakawa T, et al. Effect of CYP2C19 polymorphism on the safety and efficacy of omeprazole in Japanese patients with recurrent reflux oesophagitis. Aliment Pharmacol Ther 21: 1331-1339, 2005 (Erratum in: Aliment Pharmacol Ther 25: 1251-1252, 2007).

Department of Internal Medicine, Saga Medical School, Japan

Received for publication March 1, 2011; Accepted for publication March 1, 2011

Correspondence to Dr. Kazuma Fujimoto, fujimoto@med.saga-u.ac.jp

(C) 2011 The Japanese Society of Internal Medicine Journal Website: http://www.naika.or.jp/imindex.html 